\title{
Extractive orthopaedic treatment to compensate for skeletal Class III in preadolescents
}

\author{
Chiusolo Carmine, Gennaro Caiazzo, Luca Lombardo, Maria Paola Guarneri, Giuseppe Siciliani
}

Postgraduate School of Orthodontics of Ferrara, Ferrara, Italy.

E-mail: lulombardo@tiscali.it

Received 11 March 2011; revised 13 April 2011, accepted 30 April 2011.

\begin{abstract}
Objective: To evaluate the efficacy of extractive orthopaedic orthodontic treatment in mixed late dentition in two female patients presenting Class III malocclusion and hyperdivergent facial types due to maxillary retrusion. Materials and Methods: The orthopaedic phase, carried out using posteroanterior extraoral traction combined with rapid palatal expanders, was followed by extraction of four premolars and application of bidimensional technique fixed appliances (Boston University). Results: We achieved functional and aesthetic improvement via normalisation of the transversal dimensions and a sagittal increase in the maxilla while maintaining vertical stability. The extractions permitted resolution of the crowding problem and normalisation of the overbite and overjet, and Class I molar and canine occlusion was achieved. Conclusions: Timely intervention and exploitation of extractive space to compensate for skeletal alterations using only orthopaedic orthodontic treatment can allow achievement of excellent results.
\end{abstract}

Keywords: Extractive; Orthopaedic; Treatment

\section{INTRODUCTION}

Class III malocclusion may involve the dental component alone or it may be aggravated by a poor relationship between the maxillary and mandibular bases. In the former case, the lower molar is positioned half a cuspid towards the midline with respect to the upper molar, without skeletal alteration, whereas the latter type also involves a poor relationship between maxilla and mandible on the sagittal plane caused by maxillary retrusion and/or mandibular protrusion [1]. Patients presenting a sagittally reduced maxilla also frequently show skeletal contraction of this jaw on the transversal plane [2]. The majority of Class III patients present both dentoalveolar and skeletal components [3-5].
Various factors are implicated in the aetiology of Class III, namely heredity (e.g. race), environmental factors (e.g. functional anterior deviation of the mandible or mouth breathing, which can be a positive stimulus for mandibular growth), and several pathologies (e.g. pituitary tumours responsible for acromegaly) [6].

The incidence of this type of malocclusion in Caucasian populations varies between 1 and $5 \%$, in Asian populations it reaches an upper range which fluctuates between $9 \%$ to $19 \%$, and in Latin populations it is roughly $5 \%[7,8]$.

Early treatment of Class III malocclusion reduces the necessity of a second phase of treatment in permanent dentition [1]. However, successful orthodontic treatment of Class III preadolescents depends not only on adequate timing but also on individual growth. In fact, the decision to treat patients with moderate to severe skeletal Class III early on, or to wait until the end of growth, is a difficult one, especially as it cannot be predicted whether growth will permit successful development of the desired skeletal modifications following orthopaedic orthodontic treatment [9].

Several studies have reported that Class III skeletal discrepancies worsen with age $[10,11]$. Thus the difficulty in treating preadolescent patients successfully increases with time. Nonetheless, the majority of patients presenting severe skeletal Class III are candidates for orthognathodontic surgery, the only means of obtaining functional occlusion and aesthetic profile [12].

In early diagnosis of Class III malocclusion with maxillary deficiency in late deciduous dentition or early mixed dentition, the combination of a rapid palatal expander with posteroanterior traction is a useful treatment option [13]. This traction is often used in synergy with a maxillary expander in preadolescent patients as this device is presumed to act by opening the circumaxillary sutures and thus facilitate the orthopaedic effect of facial traction [14-16]. However, if the skeletal discrepancy is caused by excessive mandibular growth, this device seems to be of scarce therapeutic action as the impossibility of 
inhibiting of mandibular growth has been proven [17], and orthognathic surgery is the sole valid option for repositioning the mandible once growth is complete.

According to McNamara, the optimum period for initiating this orthopaedic treatment in Class III cases is in early mixed dentition [18]. Hickham on the other hand suggests that this treatment be commenced before the patient reaches eight years of age [19]. Proffit recommends that anterior retraction be started before the patient is 9 nine years old in order to produce major skeletal changes and minor dental movements [1]. Merwin et al. stated that this treatment should be begun before the patient reaches 8 years of age, or between 8 and 12 years in mixed dentition, in order to obtain more skeletal than dental modifications, achieving similar results in the two groups analysed [20]. Baccetti and McNamara verified craniofacial skeletal changes resulting from this orthopaedic treatment in both early and late mixed dentition, finding more significant results in the former group. In a review by Baccetti et al., the percentage of success was found to be $76 \%$ higher when the orthopaedic treatment plan, including extraoral traction and rapid palatal expansion, was used to treat Class III malocclusions in preadolescent patients [21].

In this context we proposed to analyse the dentoskeletal changes revealed in two patients with Class III malocclusion due to maxillary retrusion and mandibular protrusion, treated in late mixed dentition. As both patients presented moderate, and not severe, Class III-type growth, the abovementioned orthopaedic treatment (rapid expansion and traction) was applied, followed by the extraction of four premolars, to compensate for the sagittal skeletal discrepancies. In fact, orthodontic camouflage is a valid alternative to surgery in patients who do not present severe Class III malocclusion [6].

\section{CASE REPORT 1}

\subsection{Diagnosis}

Extraoral clinical examination of the female 13-year-old patient from the front showed long face, deviation of the cutaneous pogonion to the right, and mandibular asymmetry. From the side, a concave profile with evident collapse of the upper lip from hypopremaxilla could be seen (Figure 1).

Intraoral examination revealed poor oral hygiene and slight signs of periodontal damage at element 41 due to occlusal trauma. The upper arch, in permanent dentition, was greatly contracted and a space deficit was evident in the region 15-13-23. The mandibular arch was in late mixed dentition and crowding was evident in the anterior section. The sagittal occlusal relationships denoted Class III malocclusion of the molars and canines, a "head-tohead” interincisive relationship, and cross bite at 12 - 22 .
Vertically, anterior open bite was evident and transversally the lower median line was deviated to the left due to mandibular slipping (Figure 2).

Functional examination revealed a dual bite from mandibular slipping to the right aggravated by pre-contacts in the frontal region. The patient reported mixed breathing with frequent episodes of nasal obstruction. Panoramic X-ray evidenced agenesis of element 45 and the presence of third molar buds. No dentoperiodontal pathology was evident (Figure 3). Cephalometry showed malocclusion with pathological skeletal characteristics: the vertical relationships indicated severe skeletal hyperdivergence, sagittally the maxilla was retruded, the inclination of the upper and lower incisors reflected dental compensation for the skeletal malocclusion, and the position of the lips was inverted with respect to the aesthetic line (Figures 4 and 5).

\subsection{Treatment Objectives}

Analysing the problems evidenced in diagnosis we proposed transversal expansion of the upper jaw to eliminate the pre-contacts deflecting the mandible and to improve respiratory function, orthopaedic advancement of the upper jaw, resolution of the crowding in both arches, normalisation of the overjet and overbite, and improvement of the frontal and lateral aesthetic.

\subsection{Treatment Progress}

The contraction and retrusion of the upper jaw were treated using a rapid palatal expander and Delaire's pos-

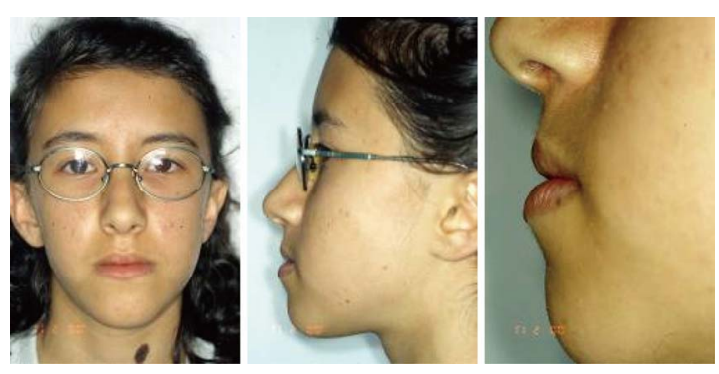

Figure 1. Extraoral photographs before treatment.

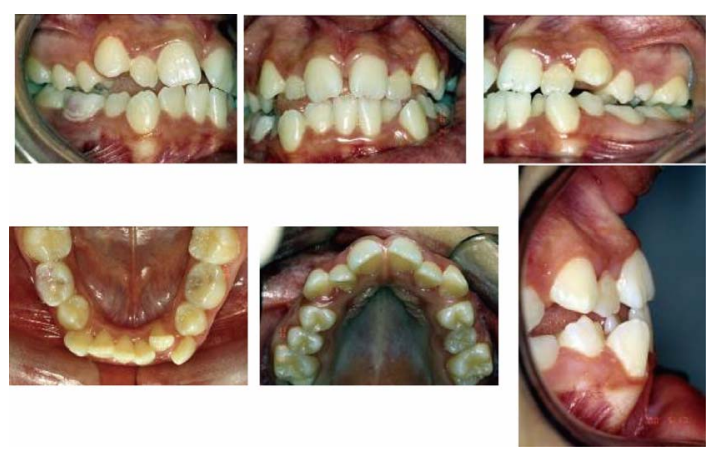

Figure 2. Intraoral photographs before treatment. 


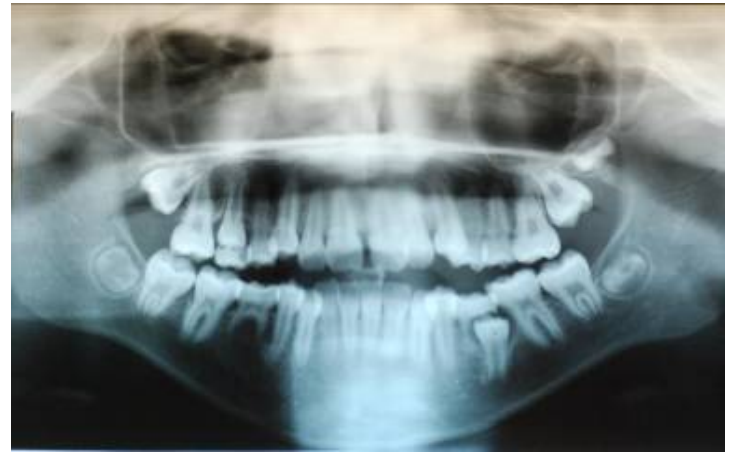

Figure 3. Panoramic X-ray before treatment.

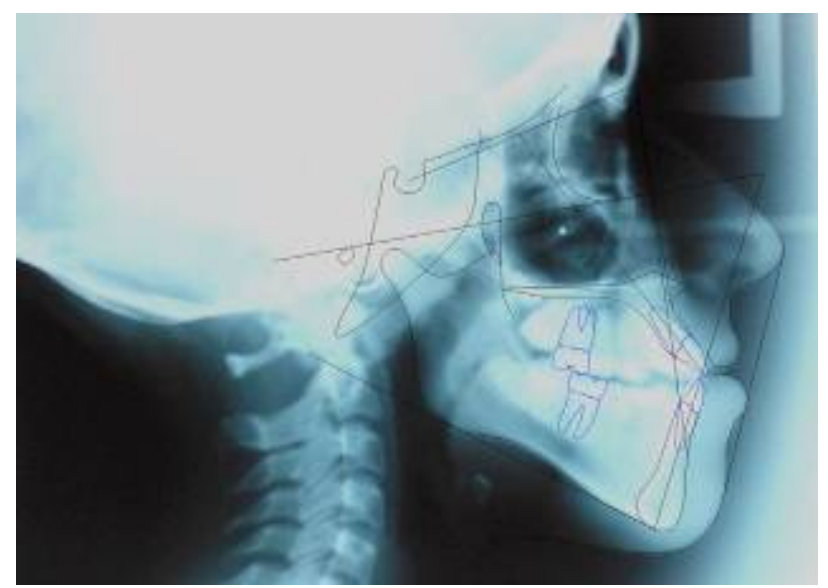

Figure 5. Cephalometric trace before treatment.

teroanterior traction, respectively. Subsequently the dental elements 14-24-34-85 were extracted and both arches were fitted with bidimensional technique fixed appliances (Boston University). Alignment was obtained using 0.016 and $0.018 \times 0.025$ pre-formed nickel-titanium wires, then extraction spaces were closed with $0.016 \times$ 0.022 steel wires together with class I intramaxillary elastics and class III intermaxillary elastics. $0.018 \times$ 0.022 ideal steel wires and vertical intermaxillary elastics were used for finishing. Finally, a Hawley retainer was employed for the upper arch and a 0.019 twist retainer was used from elements 33 to 43 in the lower.

\subsection{Treatment Results}

Frontal facial examination of the patient after treatment showed an improvement in aesthetic balance and symmetry of the mandibular position, which, however, retained its characteristics of irregularity of form, and the patient's smile was aesthetically pleasing. Lateral examination revealed a great improvement in profile aesthetics, with evident reduction in the nasolabial angle and re-equilibration of the relationship between upper and lower jaw (Figure 6). Examination of dentition exposed a Class I molar and canine relationship, normal

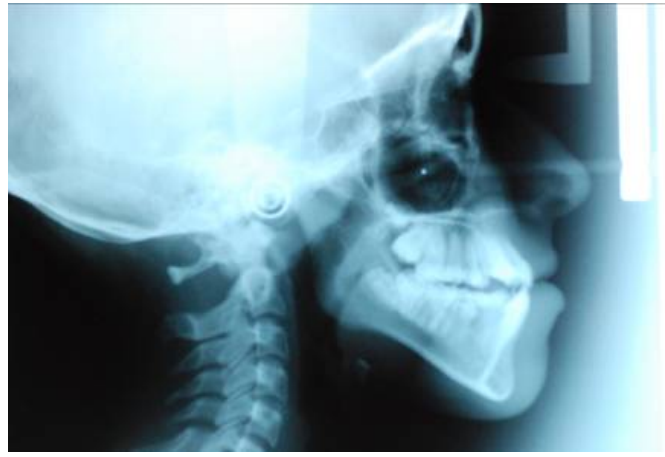

Figure 4. L-L Teleradiography before treatment.

\begin{tabular}{|c|c|c|c|c|}
\hline \multicolumn{5}{|l|}{$\begin{array}{l}\text { Valori cefalometrici } \\
\text { Maxilla to Cranial Base }\end{array}$} \\
\hline $\begin{array}{l}\left.\text { SNA( }{ }^{\circ}\right) \\
\text { Mandible to Cranial Base }\end{array}$ & 76.4 & 82.0 & 3.5 & $-1.6^{*}$ \\
\hline$\overline{\mathrm{SNB}\left({ }^{\circ}\right)}$ & 75.1 & 80.9 & 3.4 & $-1.7 * \mathrm{SN}$ \\
\hline GoGn $\left({ }^{\circ}\right)$ & 48.4 & 32.9 & 5.2 & $3.0 * * *$ \\
\hline $\begin{array}{l}\text { FMA (MP-FH) }\left(^{\circ}\right) \\
\text { Maxillo-Mandibular }\end{array}$ & 37.0 & 26.0 & 4.5 & $2.4^{* *}$ \\
\hline $\begin{array}{l}\text { ANB }\left({ }^{\circ}\right) \\
\text { Maxillary Dentition }\end{array}$ & 1.3 & 1.6 & 1.5 & -0.2 \\
\hline $\begin{array}{l}\mathrm{U} 1 \text { - NA (mm) } \\
\mathrm{U} 1 \text { - SN }\left(^{\circ}\right) \\
\text { Mandibular Dentition }\end{array}$ & $\begin{array}{c}7.4 \\
104.8\end{array}$ & $\begin{array}{c}4.3 \\
101.6\end{array}$ & $\begin{array}{l}2.7 \\
5.5\end{array}$ & $\begin{array}{l}1.1^{*} \\
0.6\end{array}$ \\
\hline $\begin{array}{l}\mathrm{L} 1-\mathrm{NB}(\mathrm{mm}) \\
\mathrm{L} 1-\mathrm{MP}\left(^{\circ}\right) \\
\text { Soft Tissue }\end{array}$ & $\begin{array}{c}7.8 \\
80.2\end{array}$ & $\begin{array}{c}4.0 \\
95.0\end{array}$ & $\begin{array}{l}1.8 \\
7.0\end{array}$ & $\begin{array}{c}2.1^{* *} \\
-2.1^{* *}\end{array}$ \\
\hline $\begin{array}{l}\text { Lower Lip to E-Plane (mm) } \\
\text { Upper Lip to E-Plane (mm) }\end{array}$ & $\begin{array}{c}0.7 \\
-7.7\end{array}$ & $\begin{array}{c}-2.0 \\
1.0\end{array}$ & $\begin{array}{l}2.0 \\
2.0\end{array}$ & $\begin{array}{c}1.4^{*} \\
-4.7^{* * * *}\end{array}$ \\
\hline
\end{tabular}

overjet and overbite, and normal transversal relationships. Oral hygiene had improved and the periodontal situation at element 41 at the beginning of treatment was better (Figure 7). Functional examination highlighted a good incisive and canine guide, and the opening movements, laterality and protrusion had normalised. Orthopantomography evidenced slight inclination of the root of element 15; the space required for third molar eruption appeared to be present (Figure 8). Cephalometric values showed sagittal improvement and vertical stability. Dental relationships were found to be in the norm (Figures 8, 9 and 10).
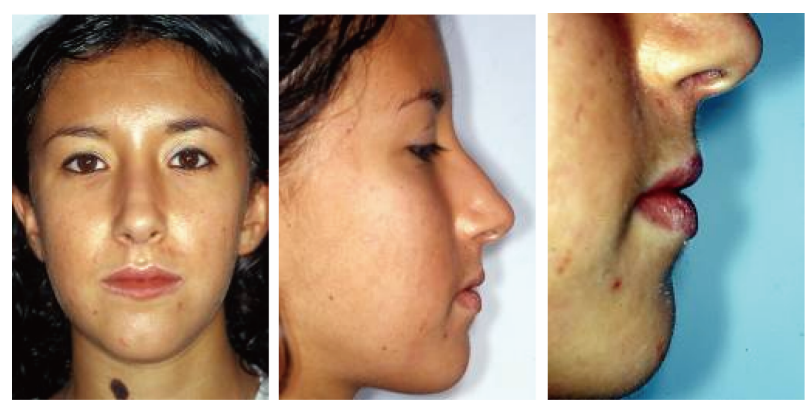

Figure 6. Extraoral photographs after treatment. 

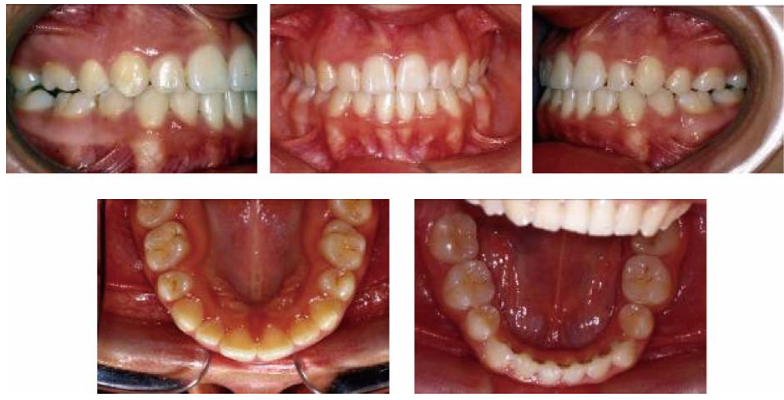

Figure 7. Intraoral photographs after treatment.

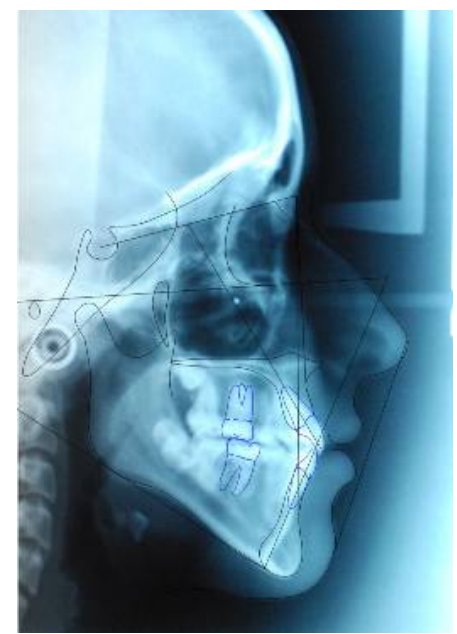

Figure 9. Cephalometric trace after treatment.

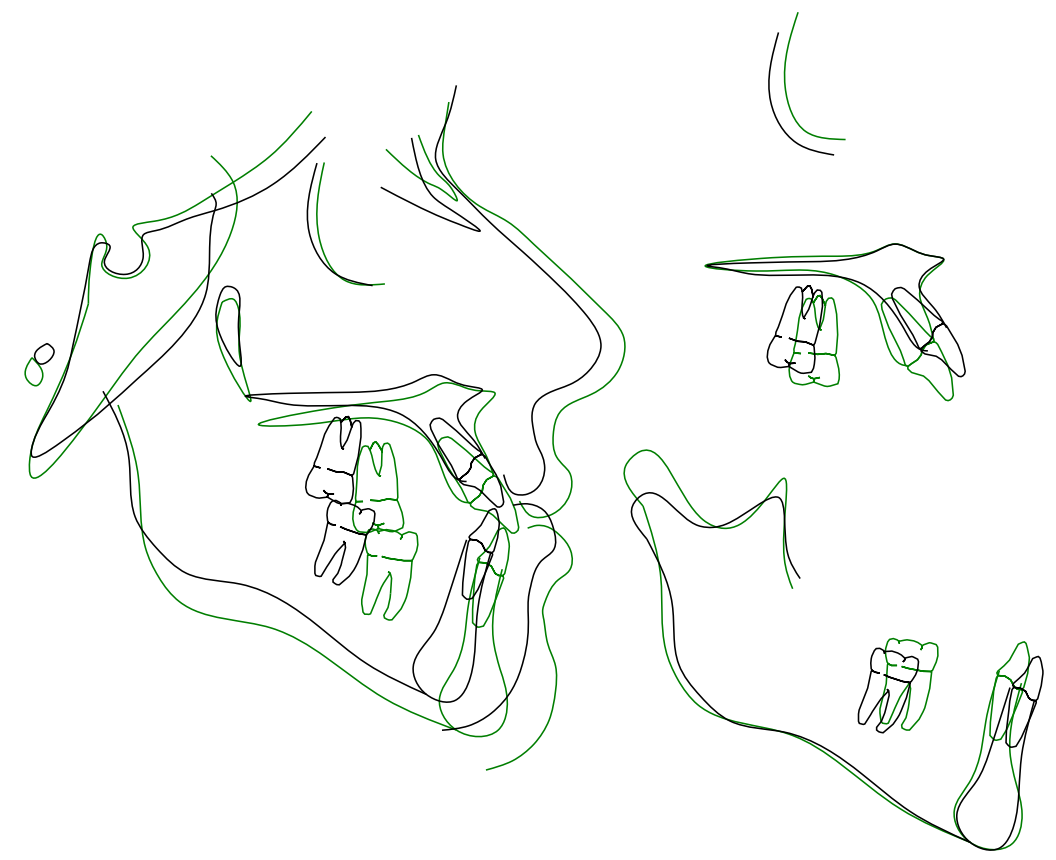

Figure 10. Superimposition of pre- and post-treatment cephalometric traces at the cranial base, passing through points $\mathrm{S}$ and $\mathrm{N}$. Superimpositions of the upper jaw were calculated on the bispinal plane, and superimpositions of the mandible on the gonion-menton plane.

\begin{tabular}{|c|c|c|c|c|}
\hline \multicolumn{5}{|l|}{ Valori cefalometrici } \\
\hline $\begin{array}{l}\text { SNA }\left({ }^{\circ}\right) \\
\text { Mandible to Cranial Base }\end{array}$ & 77.8 & 82.0 & 3.5 & $-1.2 *$ \\
\hline SNB $\left(^{\circ}\right)$ & 75.5 & 80.9 & 3.4 & $-1.6 * \mathrm{SN}$ \\
\hline GoGn $\left({ }^{\circ}\right)$ & 44.9 & 32.9 & 5.2 & $2.3^{* * *}$ \\
\hline $\begin{array}{l}\text { FMA (MP-FH) }\left({ }^{\circ}\right) \\
\text { Maxillo-Mandibular }\end{array}$ & 36.8 & 25.1 & 4.5 & $2.6^{* *}$ \\
\hline $\begin{array}{l}\text { ANB }\left(^{\circ}\right) \\
\text { Maxillary Dentition }\end{array}$ & 2.3 & 1.6 & 1.5 & 0.5 \\
\hline U1 - NA (mm) & 5.6 & 4.3 & 2.7 & 0.5 \\
\hline $\begin{array}{l}\text { U1 - SN }\left({ }^{\circ}\right) \\
\text { Mandibular Dentition }\end{array}$ & 105.5 & 102.4 & 5.5 & 0.6 \\
\hline L1 - NB (mm) & 6.9 & 4.0 & 1.8 & $1.6^{*}$ \\
\hline $\begin{array}{l}\mathrm{L} 1-\mathrm{MP}\left({ }^{\circ}\right) \\
\text { Soft Tissue }\end{array}$ & 79.8 & 95.0 & 7.0 & $-2.2^{* *}$ \\
\hline Lower Lip to E-Plane (mm) & -2.4 & -2.0 & 2.0 & -0.2 \\
\hline Upper Lip to E-Plane (mm) & -7.0 & -3.5 & 2.0 & $-1.7^{*}$ \\
\hline
\end{tabular}

Figure 8. Panoramic X-ray after treatment.

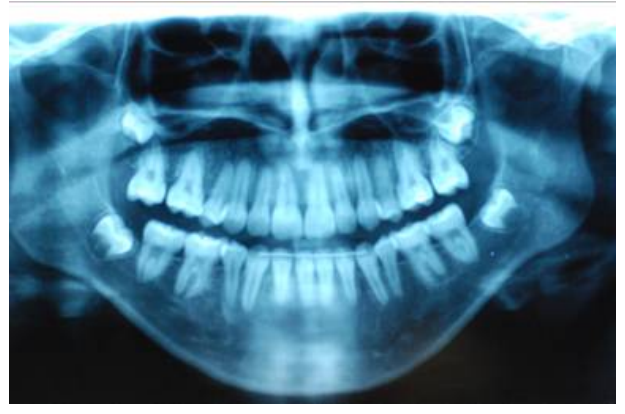




\section{CASE REPORT 2}

\subsection{Diagnosis}

The female 13-year-old patient showed a deviation of the menton to the right, a concave profile with short and retruded upper lip, and poorly accentuated zygomatic bone upon clinical examination (Figure 11). The contracted upper arch was in permanent dentition and a spatial deficit was evident in the regions of elements 12-1315-22-23. The mandibular arch was in late mixed dentition and crowding was noted in the anterior region. Analysis of the occlusion sagittally showed a Class II molar and canine relationship and cross bite throughout the anterior section, while open bite in the median section was noted upon vertical analysis and deviation of the lower median line to the right due to mandibular slipping was seen on the transversal plane (Figure 12).

Functional examination revealed dual bite from mandibular slipping to the right due to pre-contacts. The patient reported mixed breathing with frequent episodes of nasal obstruction. Panoramic X-ray showed third molar buds. No evidence of dentoperiodontal pathology was noted (Figure 13). Malocclusion with characteristics of skeletal pathology was observed by cephalometry; the vertical relationships showed severe skeletal hyperdivergence, while from the sagittal perspective the maxilla was revealed to be retruded, the inclination of the upper and lower incisors reflected dental compensation for the skeletal malocclusion and an inverted position of the lips with respect to the aesthetic line (Figure 14).
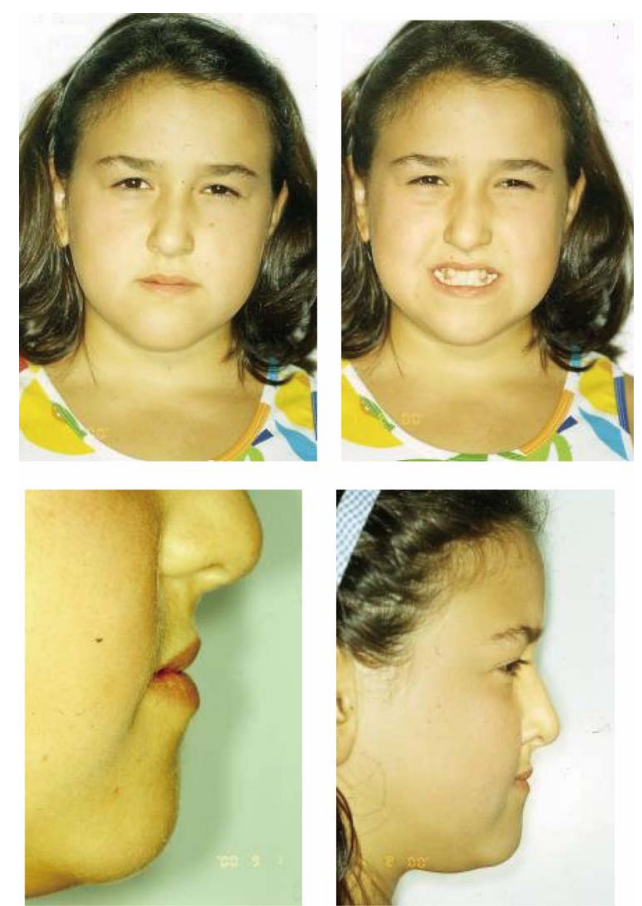

Figure 11. Extraoral photographs before treatment.
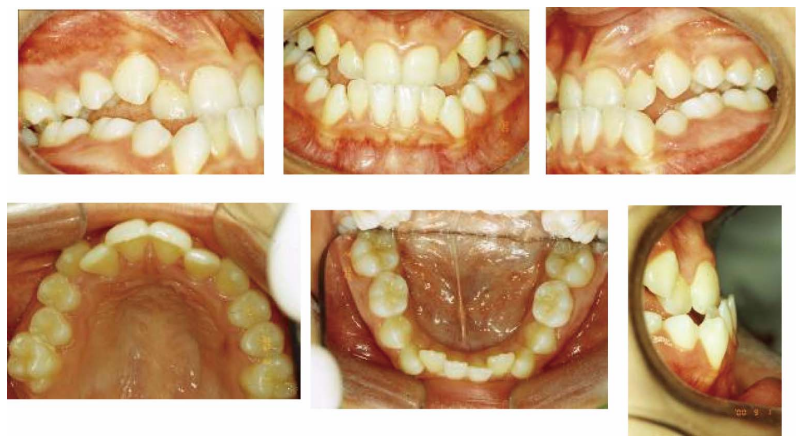

Figure 12. Intraoral photographs before treatment.

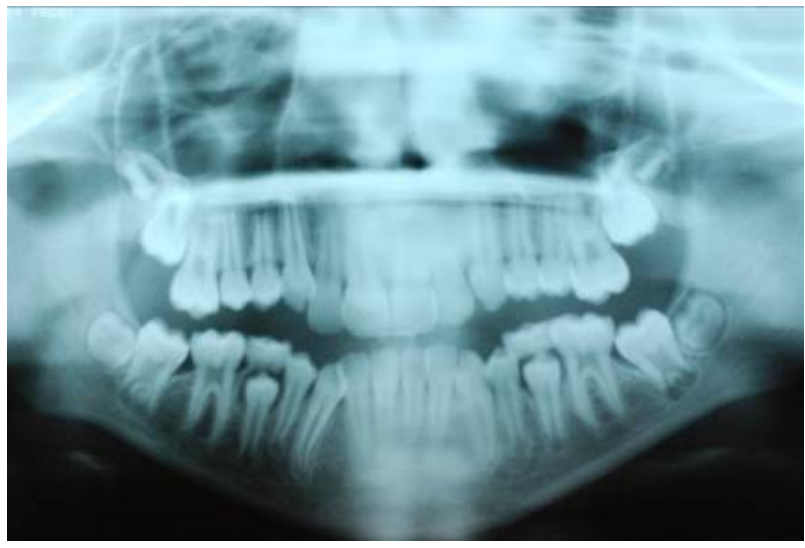

Figure 13. Panoramic X-ray before treatment.

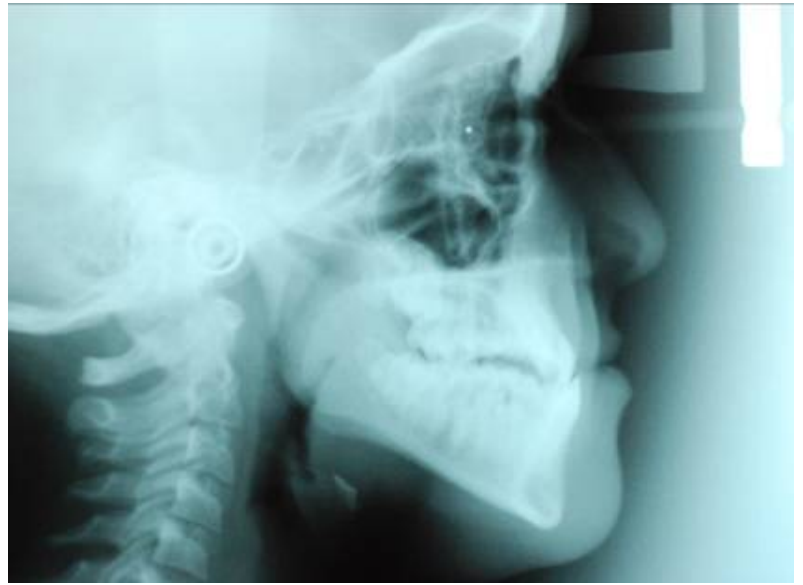

Figure 14. L-L teleradiography before treatmenent.

\subsection{Treatment Objectives}

We proposed to treat the problems evidenced in the diagnosis using transversal expansion of the upper jaw, with elimination of the pre-contacts deflecting the mandible and improvement of respiratory function, orthopaedic advancement of the upper jaw, resolution of upper and lower crowing, normalisation of overjet and overbite, and improvement of the frontal and lateral aesthetic of the face. 


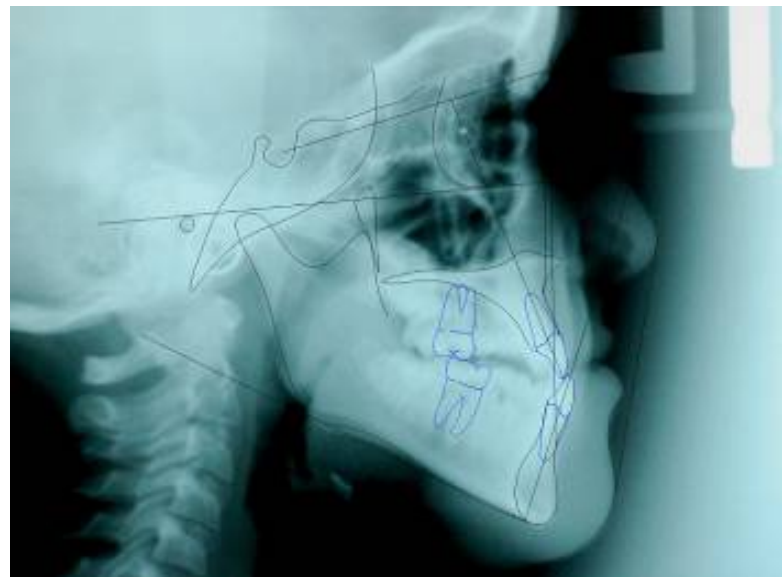

Figure 15. Cephalometric trace before treatment.

\subsection{Treatment Progress}

A rapid palatal expander and Delaire's posteroanterior traction were used to treat the contraction and retrusion of the upper jaw, respectively. The patient then underwent extraction of dental elements 14-24-34-44 and bidimensional technique fixed appliances (Boston University) were applied to both arches. 0.016 and $0.018 \times$ 0.025 pre-formed nickel-titanium archwires were employed in alignment, and $0.016 \times 0.022$ steel wires with class I intramaxillary elastics and class III intermaxillary elastics were used to close the extraction spaces. Ideal $0.018 \times 0.022$ steel wires and vertical intermaxillary elastics were used for finishing, and retention was achieved by a Hawley retainer in the upper arch and a 0.019 twist retainer from elements 33 to 43 in the lower.

\subsection{Treatment Results}

Facial examination from the front upon termination of treatment showed better aesthetic balance and mandibular symmetry, and the patient had an aesthetically pleasing smile. Lateral examination showed a much improved profile aesthetic, an evident reduction in the nasolabial angle and a re-equilibration of the relationship between upper and lower lip (Figure 16). Dental examination showed Class I molar and canine relationship, and normal overjet, overbite and transversal relationships (Figure 17). Functional examination showed a good incisive and canine guide, and normal opening movements, laterality and protrusion. Orthopantomographical analysis revealed a slight mesioinclination of the root of element 15 and the presence of space for third molar eruption (Figure 18). Cephalometric values demonstrated sagittal improvement and vertical stability. Dental relationships were normal (Figures 19 and 20).

\section{DISCUSSION}

The two cases analysed and treated both presented the
Valori cefalometrici

Maxilla to Cranial Base

SNA $\left({ }^{\circ}\right)$
Mandible to Cranial Base

SNB $\left({ }^{\circ}\right)$

GoGn $\left({ }^{\circ}\right)$

FMA (MP-FH) $\left(^{\circ}\right)$

Maxillo-Mandibular

ANB $\left({ }^{\circ}\right)$

Maxillary Dentition

$\mathrm{U} 1$ - NA (mm)

$\mathrm{U} 1$ - SN $\left(^{\circ}\right)$

Mandibular Dentition

L1 - NB (mm)

L1 - MP $\left(^{\circ}\right)$

$\underline{\text { Soft Tissue }}$

Lower Lip to E-Plane (mm)

Upper Lip to E-Plane (mm)

$\begin{array}{cccc}71.7 & 82.0 & 3.5 & -2.9^{* *} \\ 74.0 & 80.9 & 3.4 & -2.0^{* *} \mathrm{SN} \\ 41.3 & 32.9 & 5.2 & 1.6 \\ 31.0 & 26.0 & 4.5 & 1.1^{* *} \\ & & & \\ -2.3 & 1.6 & 1.5 & -2.6^{* *} \\ & & & \\ 6.5 & 4.3 & 2.7 & 0.8 \\ 94.9 & 101.4 & 5.5 & -1.2^{*} \\ & & & \\ 4.9 & 4.0 & 1.8 & 0.5 \\ 81.7 & 95.0 & 7.0 & -1.9 * \\ & & & \\ -2.4 & -2.0 & 2.0 & -0.2 \\ -7.8 & 3.2 & 2.0 & 5.5^{* * * * *}\end{array}$
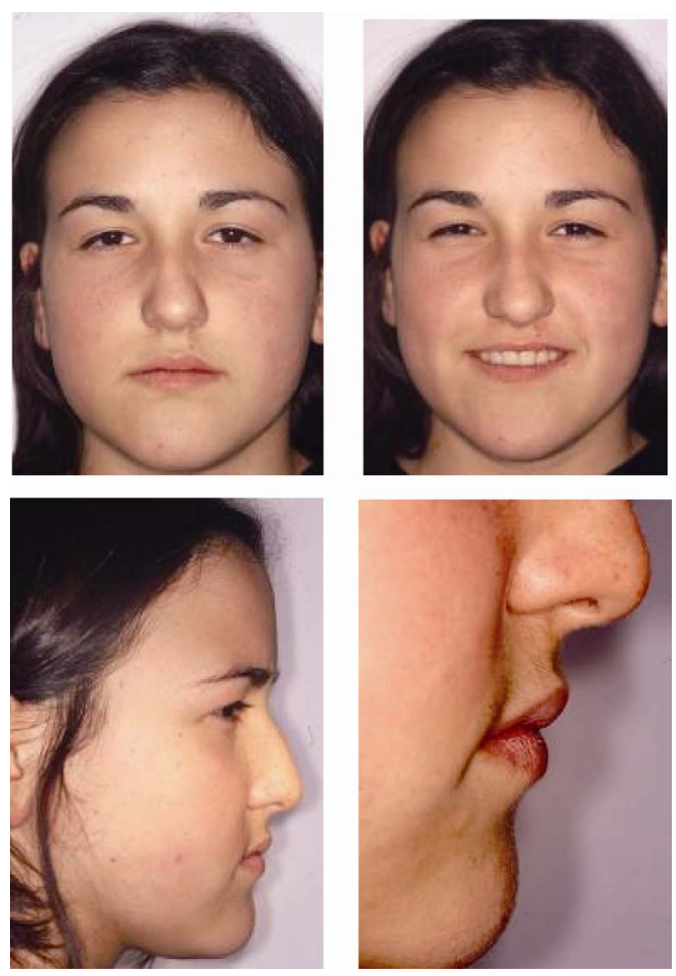

Figure 16. Extraoral photographs after treatment.
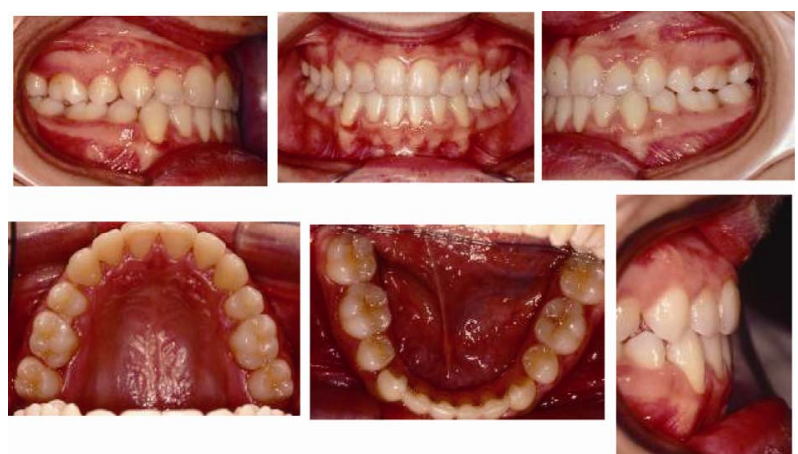

Figure 17. Intraoral photographs after treatment. 


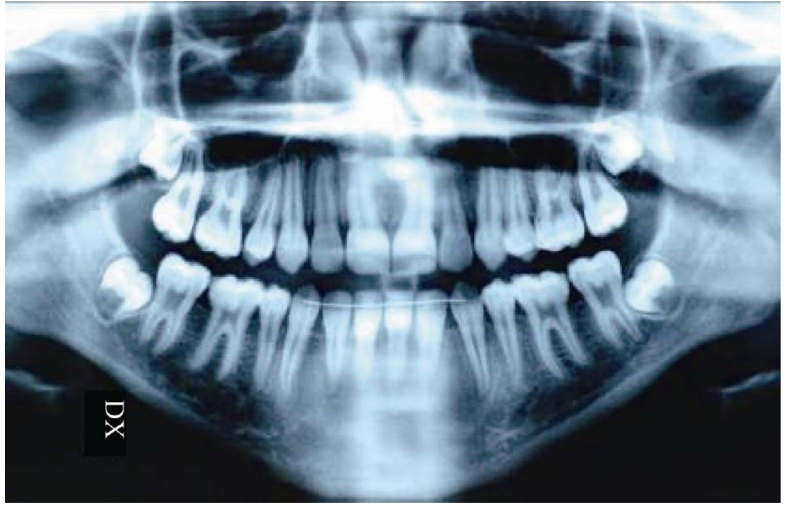

Figure 18. Panoramic X-ray after treatment.

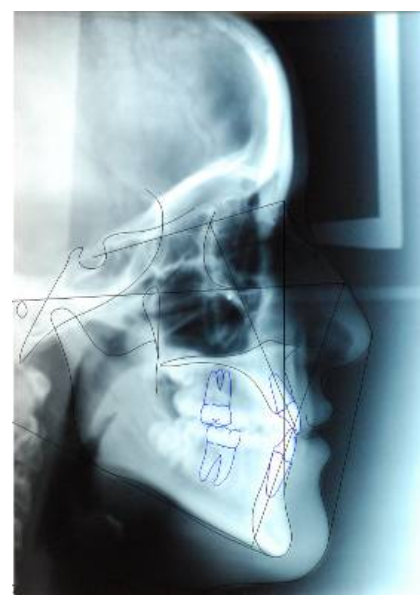

Figure 20. Cephalometric trace.

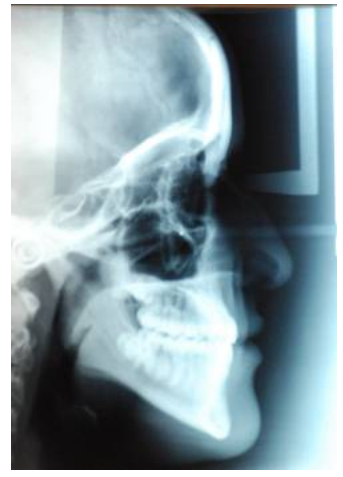

Figure 19. L-L teleradiography after treatmen.

\begin{tabular}{|c|c|c|c|c|}
\hline $\begin{array}{l}\text { Valori cefalometrici } \\
\text { Maxilla to Cranial Base }\end{array}$ & & & & \\
\hline $\begin{array}{l}\text { SNA }\left({ }^{\circ}\right) \\
\text { Mandible to Cranial Base }\end{array}$ & 73.3 & 82.0 & 3.5 & $-2.5^{* *}$ \\
\hline SNB $\left({ }^{\circ}\right)$ & 73.6 & 80.9 & 3.4 & $-2.2 * * \mathrm{SN}$ \\
\hline $\operatorname{GoGn}\left({ }^{\circ}\right)$ & 41.9 & 32.9 & 5.2 & $1.7^{*}$ \\
\hline FMA (MP-FH) $\left(^{\circ}\right)$ & 30.5 & 26.0 & 4.5 & $1.0^{*}$ \\
\hline Maxillo-Mandibular & & & & \\
\hline $\begin{array}{l}\text { ANB }\left(^{\circ}\right) \\
\text { Maxillary Dentition }\end{array}$ & -0.3 & 1.6 & 1.5 & $-1.2^{*}$ \\
\hline$\overline{\mathrm{U} 1}$ - NA (mm) & 6.3 & 4.3 & 2.7 & 0.8 \\
\hline $\begin{array}{l}\left.\text { U1 - SN ( }{ }^{\circ}\right) \\
\text { Mandibular Dentition }\end{array}$ & 96.2 & 101.4 & 5.5 & -0.9 \\
\hline L1 - NB (mm) & 3.8 & 4.0 & 1.8 & -0.1 \\
\hline L1 - MP $\left({ }^{\circ}\right)$ & 81.9 & 95.0 & 7.0 & $-1.9 *$ \\
\hline$\underline{\text { Soft Tissue }}$ & & & & \\
\hline Lower Lip to E-Plane (mm) & -6.8 & -2.0 & 2.0 & $-2.4^{* *}$ \\
\hline Upper Lip to E-Plane (mm) & -10.4 & 3.2 & 2.0 & $-6.8^{* * * *}$ \\
\hline
\end{tabular}

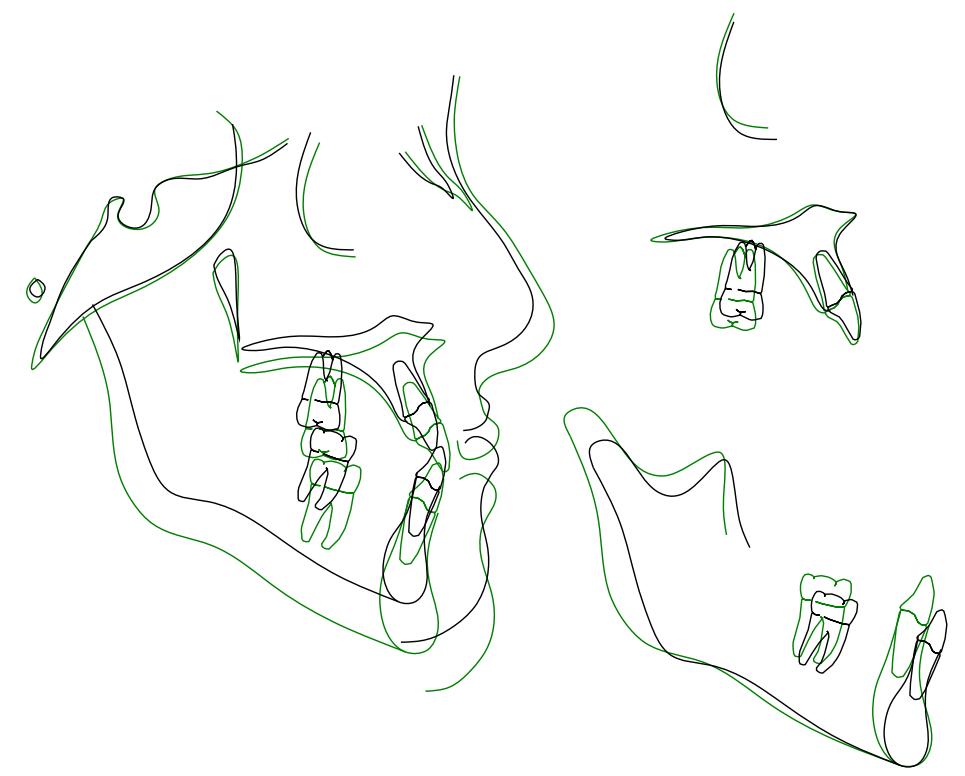

Figure 21. Superimposition of pre- and post-treatment cephalometric traces at the cranial base, passing through points $\mathrm{S}$ and N. Superimpositions of the upper jaw were calculated on the bispinal plane, and superimpositions of the mandible on the gonion-menton plane. 
characteristics of third class malocclusion with a dentoskeletal component characterised by maxillary retrusion and mandibular protrusion. These characteristics were noted upon clinical examination and subsequently confirmed by cephalometric analysis. Considering the type of malocclusion and the age of the patient, we decided to intervene immediately with the abovementioned orthopaedic treatment, using a rapid expander to correct the transversal dimension of the maxilla and posteroanterior extraoral traction to correct the sagittal discrepancy. From the literature it can be evinced that the best period to commence this treatment is early mixed dentition and Merwin et al. demonstrated that the skeletal effects of this orthopaedic treatment are evident up to 12 years of age [20].

Following on from these studies we applied these devices to patients who had just turned 13 in an attempt to open up their mandibular sutures. The treatment met with success and evident skeletal changes were seen: post-treatment cephalometry revealed an increase in the SNA angle of about $1.5^{\circ}$ in both cases treated, while the SNB did not change appreciably. This result was due to the growth induced in the upper jaw which compensated for the mandibular excess. Extraction compensated for the sagittal skeletal discrepancy, normalising the overjet and overbite relationship. Furthermore the extractions allowed us to resolve the crowding in both arches. Superimposition of the pre- and post-treatment traces showed the effect of the extractions, which permitted retrusion of the incisors and advancement of the molar, consenting achievement of the first class dental molar and canine relationship. From the superimpositions and cephalometric values it can be observed that the incisors underwent a bodily movement without significant changes in their buccal-lingual inclination. The transversal expansion of the maxilla also permitted improvement of the patient as well as function, eliminating the obstacles deflecting the mandible. Correction of the anterior sector permitted resolution of the signs of periodontal damage seen prior to treatment in the first case.

The satisfactory occlusion and the appreciable aesthetic results obtained were due to the young age of the patients treated, the choice of extraction for dentoalveolar compensation and to good collaboration in the application of traction and inter and intramaxillary elastics.

\section{CONCLUSIONS}

Our study proposed to evaluate the efficacy of orthopaedic treatment carried out with a rapid palatal expander and Delaire's posteroanterior extraoral traction in two growing patients presenting Class III malocclusion characterised by maxillary retrusion. At the end of treatment it was possible to appreciate the efficacy of these devices in normalising the sagittal and transversal discrepancies of the maxillary and mandibular bases and balancing the profile, thus obtaining a satisfactory aesthetic. Having exploited the patients' young age (acting with the correct timing) and used the extractive space to compensate for skeletal alterations, we achieved excellent results without surgery, which would probably have been necessary to achieve comparable results in an older patient.

\section{REFERENCES}

[1] Proffit, W.R. (2007) Contemporary orthodontics. 4th Edition, Mosby, St Louis, 689-707.

[2] Angelika Stellzig-Eisenhauera Christopher J. Lux and Gabriele Schuster. (2002) Treatment decision in adult patients with Class III malocclusion: Orthodontic therapy or orthognathic surgery? American Journal of Orthodontics and Dentofacial, 122, 27-38.

[3] Mackay, F., Jones. J.A., Thompson, R. and Simpson, W. (1992) Cranio-facial form in Class III cases. British journal of orthodontics, 19, 15-20.

[4] Ngan, P., Hagg, U., Yiu, C., Merwin, D. and Wie, S.H. (1997) Cephalometric comparisons of Chinese and Caucasian surgical Class III patients. International Journal of Adult Orthodontics and Orthognathic Surgery, 12, 177-188.

[5] Jacobson, A., Evans, W.G., Preston, C.G., Sadowsky, P.L. (1974) Mandibular prognathism. American Journal of Orthodontics, 66, 140-171. doi:10.1016/0002-9416(74)90233-4

[6] Dahera, W., Caron, J. and Wechslerc, M.H. (2007) Nonsurgical treatment of an adult with a Class III malocclusion, American Journal of Orthodontics and Dentofacial, 132, 243-251. doi:10.1016/j.ajodo.2006.02.034

[7] Cozza, P., Di Girolamo, R. and Nofroni, I. (1995) Epidemiologia delle malocclusioni su un campione di bambini delle scuole elementari del Comune di Roma. ortognatodonzia (Italian), 4, 217-228.

[8] Silva, R.G. and Kang, D.S. (2001) Prevalence of malocclusion among Latino adolescents. American Journal of Orthodontics and Dentofacial Orthopedics, 119, 313-315. doi:10.1067/mod.2001.110985

[9] Kanno, Z., Kim, Y. and Soma, K., Early correction of a developing skeletal Class III malocclusion, The Angle Orthodontist, 77, 549-556. doi:10.2319/0003-3219(2007)077[0549:ECOADS]2.0.C $\mathrm{O} ; 2$

[10] Dietrich, U.C. (1970) Morphological variability of skeletal Class III relationships as revealed by cephalometric analysis. Report of the Corgress, European Orthodontic Society, 46, 131-143.

[11] Guyer, E.C., Ellis, E.E., McNamara, J.A. and Behrents, R.G. (1986) Components of Class III malocclusion in juveniles and adolescents. Angle Orthodontist, 56, 7-30.

[12] Lin, J.X. and Gu, Y. Preliminary Investigation of Nonsurgical Treatment of Severe Skeletal Class III Malocclusion in the Permanent Dentition. Angle Orthodontis, 73, 401-410.

[13] Baccetti, T., McGill, J.S., Franchi, L., McNamara Jr, J.A. 
Tollaro, J. (1998) Skeletal effects of early treatment of Class III malocclusion with maxillary expansion and face-mask therapy. American Journal of Orthodontics and Dentofacial Orthopedics, 113, 333-343. doi:10.1016/S0889-5406(98)70306-3

[14] Haas, A.J. (1965) Treatment of maxillary deficiency by opening the midpalatal suture. Angle Orthodontist, 65, 200-217.

[15] Haas, A.J. (1970) Palatal expansion: Just the beginning of dentofacial orthopedics. American Journal of Orthodontics, 57, 219-255. doi:10.1016/0002-9416(70)90241-1

[16] McNamara Jr, J.A. and Brudon, W.L. Orthodontic and orthopedic treatment in the mixed dentition. Needham Press, Ann Arbor, 1993.

[17] Fields, H.W. and Proffit, W.R. (2000) Treatment of skeletal problems in preadolescent children. In: Proffit, W.R. and Fields, H.W. Eds., Contemporary Orthodontics, 3rd Edition, Mosby, St Louis, 511-515.

[18] McNamara, J.A. (1994) Mixed dentition treatment. In: Graber, T.M. and Vanarsdall, R.L. Eds., OrthodonticsCurrent Principles and Techniques. Mosby Year Book, St Louis, 508.

[19] Hickham, J.H. 1991, Maxillary protraction therapy: Diagnosis and treatment. Journal of Clinical Orthodontics, 25, 102-113.

[20] Merwin, D., Ngan, P., Hagg, U., Odont, Dr., Yiu, C. and Wei, S.H.Y. (1997) Timing for effective application orthopedic force to the maxilla of anteriorly directed. American Journal of Orthodontics and Dentofacial Orthopedics, 112, 292-299. doi:10.1016/S0889-5406(97)70259-2

[21] De Toffol, L., Pavonia, C., Baccetti, T., Franchi L. and Cozza, P. (2008) Orthopedic treatment outcomes in Class III malocclusion. A systematic review, Angle Orthodontist, 78, 561-573. doi:10.2319/030207-108.1 